\title{
GENDER AND MULTIDIMENSIONAL POVERTY IN LESOTHO
}

\section{Paramaiah Ch}

Associate Professor, School of Business, Skyline University College, Sharjah, United Arab Emirates

\author{
Nthabeleng Joyce Sakoane and R. Machema
}

Department of Economics, National University of Lesotho, Lesotho, Southern Africa

\section{Charity Gomo}

Department of Economics and Finance, University of the Free State, South Africa

\begin{abstract}
This study applies the Alkire \& Foster (2011) approach to estimate gender gaps in multidimensional poverty in Lesotho using 2016 population and housing census dataset. Results show that when using three-dimensions; education, health and living-standards, gender-gaps observed in multidimensional poverty are above $20 \%$ in all age groups except for adults implying that females are more vulnerable compared to males. However; when adding the fourth dimension, economic activity that captures employment status leads to larger estimates of male poverty than female. We conclude that overall, poverty seems to be feminized in Lesotho and on average the rural population suffers more from deprivation in all the indicators considered. Two strong policy implications arise from our findings i.e. reduction of the rural-urban poverty gap and gender gap. It is recommended that some serious protective measures to combat poverty should be taken in rural areas to address equality issues to comprehend the Sustainable Development Goals.
\end{abstract}

KEYWORDS: Gender, Lesotho, Multidimensional poverty.

JEL Classification I3.132. N37

Article Received: 10 August 2020, Revised: 25 October 2020, Accepted: 18 November 2020

\section{INTRODUCTION BACKGROUND OF THE STUDY}

Poverty involves not having enough means to meet basic needs such as food, shelter and clothing. Just one indicator cannot apprehend the multiple features of well-being that represents poverty such as economic, social and material. This means that focusing on income alone is not enough to apprehend the accurate existence of poverty. Because of this recognition, poverty research has moved attention from using a one-dimensional measure to a multidimensional approach. According to the Oxford Poverty and Human Development Initiative (OPHI), multidimensional poverty consists of several factors that forms poor people's experience of hardship such as poor health, lack of education, inadequate living standard, lack of income, disempowerment, poor quality of work and threat from violence (see, https://ophi.org.uk/policy/multidimensionalpoverty-index/). Multidimensional poverty measures include a range of dimensions and indicators to capture the complexity of poverty and better inform policies to alleviate deprivation. Different indicators appropriate to the society and situation can be chosen. These indicators divulge different drawbacks experienced by poor people.. Multidimensional poverty measures can be categorised to disclose poverty levels amid distinct subgroups of people and also in various parts of a country

There is a large body of literature on multidimensional poverty (See, Alkire and Foster (2011); Datt (2019); Espinoza-Delgado and Klasen (2018); Masood et al. (2011) and Wu Yichao and Qi Di (2017)). However, most existing multidimensional poverty measures have used the household as the unit of analysis, that is the multidimensional poverty situation of the household was treated similar to that of its members (Espinoza-Delgado and Klasen 2018).. The household-based poverty measures disregard the intra-household inequalities and as a result they don't consider gender differentials, leading to underestimation of the extent of overall poverty and inequality in the society, which 
could in turn lead to biased assessments of social policies (Rodríguez 2016). As a result, gender difference and analysis cannot be estimated or performed using household-based measures, as the gender gap in poverty will not be captured (Wiepking and Maas 2005).

Poverty reduction and gender equality are primary development goals in many developing countries including Lesotho. In recent years, gender inequality is not just a source of women's poverty but also an obstacle to addressing poverty in general and thus, gender inequality hinders progress across development outcomes causing poverty.
Having committed itself to gender equality and alleviation of poverty, Lesotho has taken measures towards achieving these commitments. In recent years, the Government of Lesotho (GoL) has enacted laws that protect women's rights though the impact of implementation is yet to be realised. Such laws among others include the Companies Act of 2011 and other laws concerning economic transactions and property rights. Nevertheless, Poverty has remained a widespread in Lesotho; there is virtually no progress in reducing extreme poverty between 2002 and 2010. Figure 1.1 shows the poverty trends from 2002 and Gross Domestic Product (GDP).

\section{Figure 1.1: Poverty rates and GDP per capita}

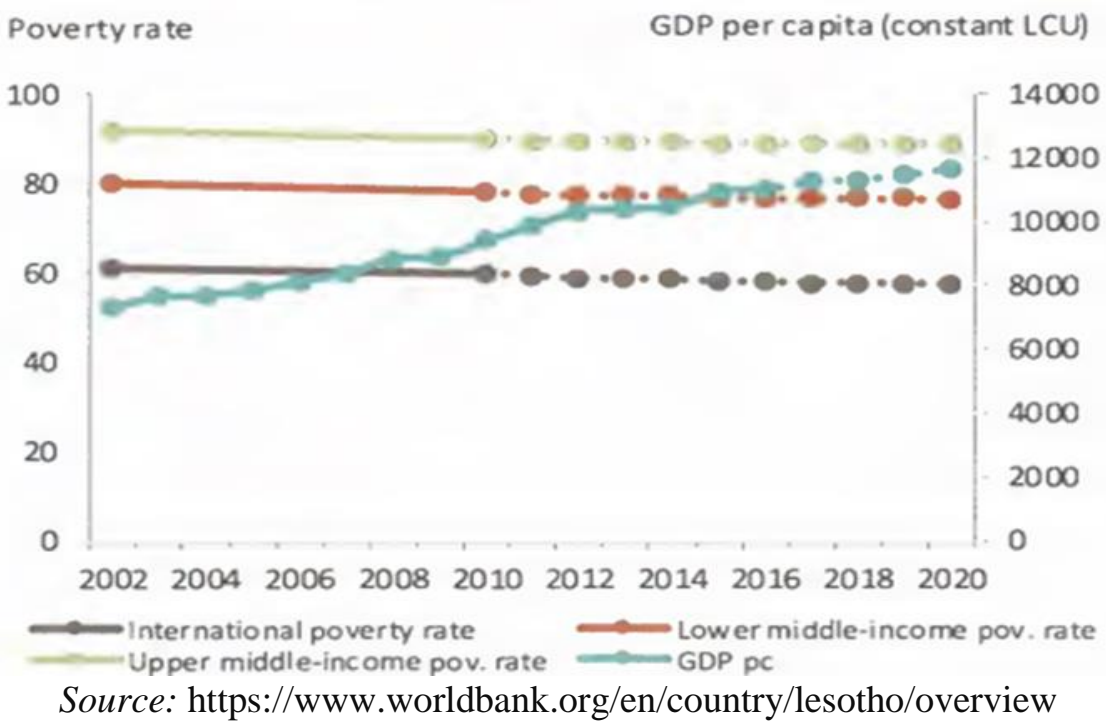

The headcount poverty rate based on the international poverty line of United States Dollar (USD) 1.90 per person per day was almost stagnant during the 2000s, falling slightly from 61.3 percent in 2002 to 59.7 percent in 2011. Estimates for 2018 suggest that 53.7 percent of the population is still trapped under the USD1.90 poverty line. ${ }^{1}$

\footnotetext{
${ }^{1}$ The international poverty line is a monetary threshold under which an individual is considered to be living in poverty and poverty line is the minimum income level used as an official standard for determining the proportion of population living in poverty. It can be based on income or consumption levels. Households whose incomes fall below this line are considered very poor.
}

This persistently high rate of poverty in Lesotho can be explained by several factors such as, decreased remittance inflows that Lesotho citizens formerly received from their migrant family members working in South African (SA) mines, declines in livestock productivity as stock theft and rangeland deterioration have made animal husbandry an unattractive source of income resulting in high unemployment rate. According to the information published on the global economy website, unemployment rate in Lesotho is estimated around 23.6 percent in 2018

(See,

https://www.theglobaleconomy.com/lesotho/u nemployment_rate/).

Poverty in Lesotho is deeply established in rural areas with a poverty head count rate of 59.6 percent compared with urban head count 
rate of 39 percent. When broken down by region, it is clear that rural communities contain the vast majority of the country's poor. This is mainly as a result of low agricultural sector performance, which is the main source of income in rural areas, caused by drought in 2016 and because many young people migrate to urban areas leaving farming as a livelihood (Rocchi and Del Sette 2016).

Achieving gender equality in Lesotho is a complex process given the highly benevolent nature of its society and culture. In Lesotho, the male is head and heir of the family. These cultural and traditional practices tend to discriminate women with respect to decisionmaking processes and ownership of property or of some assets in all areas of their lives. Majority of men in Lesotho fail to see women as their equal peers. This situation results in gender inequalities, which may in turn lead to gender-based violence. Approximately $86 \%$ of women in Lesotho experience gender-based violence perpetrated by men in their lifetime, (Lesotho Country Analysis report 2017). For instance, women in Lesotho make up a majority of the agricultural labour force and contribute substantially towards sustainable livelihoods and economic development of the country. However, majority of them are not able to own land or access financial services which means they cannot use their plots to secure loans and invest in improvements such as irrigation and machinery. This inadequate rate of progress toward alleviation of poverty in Lesotho raises important questions about the concept and understanding of poverty and deprivation as well as policies and strategies that have been adopted to achieve poverty reduction so far.

Some studies have assessed an individualbased multidimensional poverty measure across the entire population (Vijaya et al. (2013); Klasen and Lahoti (2016); Correa (2017); Wu Yichao and Qi Di (2017); and Espinoza-Delgado and Klasen (2018)). However, due to lack of sex-disaggregated data, these studies have partly succeeded in analysing gender and multidimensional poverty. This paper will be one of the first few attempts in Lesotho to study gender and multidimensional poverty analysis. Additionally, to the best of our knowledge, none of the local studies examined multidimensional poverty measure and estimated gender differentials in the incidence and intensity of multidimensional poverty for the whole population of Lesotho using the most recent 2016 population and housing census dataset. The 2016 census dataset permits us to include extra dimensions and indicators to the original Multidimensional Poverty Index (MPI) to derive or propose MPI for the context of Lesotho. For instance, we included labour market activities as the fourth dimension for deriving the MPI since not all these studies mentioned included labour market activities as an indicator for deriving MPI. With persistently high unemployment rate being one of the major causes of poverty, it is crucial to include this dimension. In addition, employment is a dimension of gendered poverty that exists in the literature on gender equality; in which women face higher impoverishment levels than men.

The objectives of this paper is to propose a multidimensional poverty framework to estimate gender differences in multidimensional poverty for the whole population in Lesotho and to identify the indicators/dimensions contributing most to poverty between men and women with specific focus on rural-urban areas.

This paper is organised as follows, Section 2 presents the data and methodology. In particular, it describes the data sources, dimensions, indicators and the methodology used. Section 3 presents and discuss the results of empirical analysis. Section 4 presents the robustness analysis and the last section conclude by discussing main findings of the results and limitations of the paper as well as the policy recommendations based on the findings of the study.

\section{METHODOLOGY}

\subsection{Data}

The data adopted for this analysis was from Lesotho 2016 Population and Housing Census dataset, conducted by Bureau of Statistics. The census is nationally representative and provides information among others on the demographics, educational attainment, economic activity, household characteristics and housing possessions, disability and albinism for all persons, deaths of household members, and fertility for women aged 12-50 years. The population will be divided into four age groups: children $(<6$ years old $)$, 
adolescents (between 6 and 17 years), adults (between 18 and 59 years) and elderly (60 years or older).

\subsection{Summary Statistics}

The data was first analysed using the summary statistics shown in Table 2.1, which presents the dimensions that will be used in this paper. Education shows the highest educational level completed by all persons aged three years and above. We see that more people are attending primary school, this might be due to the introduction of free primary education in the year 2000; the number of people attending primary school has increased even though a coverage problem is noticeable when more years of schooling are added. Secondary and tertiary education are still very behind as compared to primary education.
The health dimension is measured by disability. Only 2.27 percent of the entire population is disabled while the rest is not disabled. From the living standards dimension, most houses in Lesotho use sand/ concrete blocks for walls, corrugated iron for roofing and cement for floor. Main source of energy for cooking is wood and paraffin is used as the main energy for lighting. Public tap is the main source of drinking water that is used by most households and the most used sanitation facility is the Ventilated Improved Pit Latrine (VIP) while mattress and cell phone are the most owned assets. Lastly, the employment status shows that 28.29 percent of the population is employed and only 4.33 percent is unemployed. However, 67.28 percent records missing information with regards to this indicator.

Table 2.1: Summary Statistics of the Data

\begin{tabular}{|c|c|c|}
\hline Dimensions & Indicators & Percentage \\
\hline \multirow{5}{*}{ Education } & Highest educational level completed: Primary & 47.85 \\
\hline & Secondary & 26.94 \\
\hline & Graduate & 2.07 \\
\hline & Never Attended & 8.32 \\
\hline & Other & 14.82 \\
\hline \multirow[t]{3}{*}{ Health } & Disability: Disabled & 2.27 \\
\hline & Not disabled & 87.76 \\
\hline & Missing & 9.97 \\
\hline \multirow[t]{24}{*}{ Living Standards } & Cooking Fuel: Wood & 45.98 \\
\hline & LPG & 23.57 \\
\hline & Electricity grid & 11.56 \\
\hline & Other & 18.89 \\
\hline & Lighting: Paraffin & 50.25 \\
\hline & Electricity grid & 33.51 \\
\hline & Candle & 13.36 \\
\hline & Other & 2.88 \\
\hline & Sanitation : VIP & 39.02 \\
\hline & Unimproved pit latrine & 30.36 \\
\hline & Open defecation (bush/field) & 21.91 \\
\hline & Other & 8.71 \\
\hline & Drinking water: Public tap & 39.3 \\
\hline & Piped into yard/plot & 22.48 \\
\hline & Unprotected spring & 12.3 \\
\hline & Other & 25.92 \\
\hline & Asset ownership: Radio & 52.98 \\
\hline & Television & 29.92 \\
\hline & Cellular phone & 82.69 \\
\hline & Scotch cart & 8.99 \\
\hline & Mattress & 87.61 \\
\hline & Refrigerator & 22.73 \\
\hline & Stove & 59.42 \\
\hline & Computer & 8.09 \\
\hline
\end{tabular}




\begin{tabular}{|c|c|c|}
\hline & Car & 10.23 \\
& & \\
& & \\
& & \\
& & \\
& & \\
& Housing & 39.37 \\
& Wall: Sand/concrete blocks & 33.62 \\
Stone with mud & 10.89 \\
& Stone with lime/cement & 16.12 \\
Other & 61.75 \\
& Roof: Corrugated Iron & 30.97 \\
Thatch/grass/straw & 7.28 \\
Other & 33.36 \\
& Floor: Cement & 33.23 \\
Mud/dung & 12.12 \\
& Vinyl/Linoleum & 21.29 \\
\hline Other & 28.29 \\
& Enemployed & 4.33 \\
& Missing & 67.28 \\
\hline
\end{tabular}

Source: Authors' calculations

2.3

\section{Multidimensional Poverty Measure}

The global MPI uses a methodology introduced in 2011 by Alkire and Foster to measure multidimensional poverty across countries. In this paper, we will use the MPI methodology to estimate a multidimensional poverty in Lesotho. The global MPI consists of three dimensions: health, education and living standard. In addition each dimension is broken down into indicators, in total: health dimension consists of nutrition and child mortality, education dimension accounts for years of schooling and school attendance, and living standard dimension includes cooking fuel, drinking water, sanitation, electricity, housing and asset ownership. Each dimension is equally weighted and each indicator within a dimension is equally weighted. A person is identified as multi-dimensionally poor if they are deprived in at least one third of the weighted indicators, (Oxford Poverty and Human Development Initiative (OPHI) 2017).

MPI is the multidimensional poverty index, which is the product of incidence and Intensity. Incidence shows the percentage of people who are poor (or headcount ratio, $\mathrm{H}$ ) while intensity is the average share of indicators in which poor people are deprived
(A). This approach is very flexible in terms of the inclusion of dimensions and indicators. It can be categorised by geographic area, ethnicity, or other sub-groups of a population to show the composition of poverty within and among these groups. This method can be used with different indicators, weights and cut-offs to develop national MPIs that reflect the priorities of individual countries, (OPHI 2017). To assess gender differences in poverty, we will use the sex/poverty ratio presented by Mc Lanahan et al., (1989) which is the ratio of women's poverty rate to the men's poverty rate. If the ratio is greater than one, it means that women have a higher poverty rate than men.

\subsection{Dimensions, Indicators and Deprivation Cut-off}

For the case of Lesotho, numerous adaptions will be made to the original MPI in terms of the dimensions and indicators chosen and respective cut-off points of the indicators to cater for Lesotho's context of poverty and create an improved local version of the MPI. This multidimensional poverty measure consists of four equally weighted dimensions: economic activity is an added dimension to the global MPI. Table 2.2 shows the dimensions 
and the indicators to be used to measure each of them and the deprivation cut-offs. We will use schooling achievement as the indicator for education. According to the National Policy for Integrated Early Childhood Care and Development in Lesotho, many studies have shown that in addition to provision of services for children from 0 to 3 years, quality preschool education for children from 3 to 5 years old is essential for improving educational outcomes and reducing the costly internal inefficiencies of the school system. Therefore, for children, we will evaluate if they are currently attending pre-school. For adolescents, we will evaluate if they have completed primary school. Finally, adults and elderly are deprived in education if they have not completed at least lower secondary school. In the global MPI, the health dimension includes child mortality and nutrition as the two indicators. The 2016 population census data set does not have any information on malnutrition, hunger or food security. Disability will be used as an indicator because it is associated with lower living standards, greater likelihood of marginalization and discrimination, through its unfavorable impact on human capital formation opportunities in childhood, employment opportunities and productivity in adulthood (World Health Organization \& World Bank 2011). The deprivation cut-off for this indicator is the presence of at least one disabled household member.

We use six indicators to measure living standards dimension, housing, drinking water, sanitation, cooking fuel, electricity and assets as per the 2018 global MPI. Economic activity will be included as the fourth dimension with employment status as the indicator since unemployment is one of the major causes of povertyin Lesotho, it is important to include this dimension. The respondents were asked of their main activity status in the past 7 days before the survey. A household is deprived in economic activity if all household members aged 15 to 65 are unemployed. Table 2.2 presents the dimensions, indicators and deprivation cut- offs which were used.

Table 2.2: Dimensions, Indicators \& deprivation cut-offs

\begin{tabular}{|c|c|c|}
\hline Dimension & Indicator & Deprivation indicators: he/she is deprived if he/she \\
\hline Education & $\begin{array}{c}\text { Schooling } \\
\text { Achievement }\end{array}$ & $\begin{array}{l}\text { (Children) is not attending pre-school. } \\
\text { (Adolescents) have not completed primary school. } \\
\text { (Adults) have not completed lower secondary school. } \\
\text { (Elderly) have not completed lower secondary school. }\end{array}$ \\
\hline Health & Disability & If at least one household member is disabled. \\
\hline Standard of Living & $\begin{array}{c}\text { Housing } \\
\text { Drinking water } \\
\text { Assets }\end{array}$ & $\begin{array}{c}\text { Is living in a house that the floor is made of natural } \\
\text { materials or the roof or walls are made of low quality } \\
\text { materials. } \\
\text { Household does not have access to an improved } \\
\text { drinking water or safe drinking water is within } 30 \\
\text { minutes' walk from home, round-trip. } \\
\text { Household does not own more than one of the } \\
\text { following assets: radio, television, cellular phone, } \\
\text { animal cart, car, electric/gas/coal stove, } \\
\text { computer/laptop or refrigerator and does not own a } \\
\text { bed/mattress. } \\
\text { Is living in a household, which uses wood, coal, } \\
\text { animal dung, crop waste, and straw/shrubs/grass as } \\
\text { main cooking fuel. } \\
\text { Is using unimproved sanitation facility or it is } \\
\text { improved but shared with other households. } \\
\text { If the household has no electricity. }\end{array}$ \\
\hline Economic Activity & Employment status & $\begin{array}{l}\text { If all household members aged, } 15 \text { to } 65 \text { years are } \\
\text { unemployed. }\end{array}$ \\
\hline
\end{tabular}

Source: Modified version of Espinoza- Delgado and Klasen (2018) 


\section{EMPIRICAL ANALYSIS AND RESULTS}

3.1 The Incidence and Intensity of Multidimensional Poverty

Using a poverty cut-off of $33.33 \%$, Table 3.1 displays the incidence of the multidimensional headcount ratio $(H)$, the average deprivation shares across the multi-dimensionally poor $(A)$, the adjusted headcount ratio $\left(M_{o}\right)$, as well as the calculation of the corresponding gender gaps in both absolute and relative terms.

Table 3.1: Multidimensional Poverty by age group, gender $\&$ gender-gaps

\begin{tabular}{|c|c|c|c|c|}
\hline \multirow[b]{3}{*}{ Subgroup } & Male & Female & \multicolumn{2}{|c|}{ Differences between } \\
\hline & & & \multicolumn{2}{|c|}{ females \& males estimates } \\
\hline & $\mathrm{H}(\%)$ & H (\%) & Absolute & Relative \\
\hline \multicolumn{5}{|c|}{ The multidimensional headcount ratio $(H):$ The incidence of multidimensional poverty } \\
\hline Children & 10.3 & 16.2 & 5.9 & 1.57 \\
\hline Adolescents & 13 & 15.8 & 2.8 & 1.22 \\
\hline Adults & 54.9 & 33.7 & -21.2 & 0.61 \\
\hline Elderly & 21.8 & 34.3 & 12.5 & 1.57 \\
\hline The whole population & 61.8 & 38.2 & -23.6 & 0.62 \\
\hline \multicolumn{5}{|c|}{ Differences between } \\
\hline \multirow[b]{2}{*}{ Subgroup } & & & \multicolumn{2}{|c|}{ females \& males estimates } \\
\hline & $\mathrm{A}$ & $\mathrm{A}$ & Absolute & Relative \\
\hline \multicolumn{5}{|c|}{ The average deprivation share among the poor $(A)$ : The intensity of multidimensional poverty } \\
\hline Children & 0.951 & 1.006 & 0.055 & 1.058 \\
\hline Adolescents & 0.931 & 0.924 & -0.007 & 0.992 \\
\hline Adults & 0.998 & 0.994 & -0.004 & 0.996 \\
\hline Elderly & 1.064 & 1.085 & 0.021 & 1.020 \\
\hline The whole population & 1.024 & 0.961 & -0.063 & 0.938 \\
\hline \multirow[b]{3}{*}{ Subgroup } & Male & Female & \multicolumn{2}{|c|}{ Differences between } \\
\hline & & & \multicolumn{2}{|c|}{ females \& males estimates } \\
\hline & $M_{o}$ & $M_{o}$ & Absolute & Relative \\
\hline \multicolumn{5}{|c|}{ The adjusted multidimensional headcount ratio $($ Mo $):$ MPI index $(H \times A)$} \\
\hline Children & 0.098 & 0.163 & 0.065 & 1.663 \\
\hline Adolescents & 0.121 & 0.146 & 0.025 & 1.207 \\
\hline Adults & 0.548 & 0.318 & -0.23 & 0.580 \\
\hline Elderly & 0.232 & 0.372 & 0.14 & 1.603 \\
\hline The whole population & 0.633 & 0.367 & -0.266 & 0.580 \\
\hline
\end{tabular}

\section{Source: Authors' calculations}

We find that in Lesotho, the gender gaps in the incidence of multidimensional poverty and in adjusted multidimensional headcount ratio in relative terms are estimated to be above $20 \%$ in all age groups except for adults, which means that females experience more deprivations than males. The highest gender gap in poverty incidence and MPI index is found among children and the lowest among adolescents. These gender gaps observed among children, adolescents and elderly are in favour of males, but the reverse is the case among adults: Adults men are worse off by $42 \%$ than females in terms of MPI index and by $39 \%$ in terms of incidence of poverty.
It can also be observed from Table 3.1 that overall both men and women are likely to suffer from the same intensity of multidimensional poverty. We can therefore conclude that the size and the direction of the estimated gender gaps in MPI index are mostly driven by the differences observed in the incidence of poverty. Considering the whole population, the gender differences in multidimensional poverty are below $45 \%$ and poverty seems to be feminized in that women seem to be better off than men in poverty incidence by $38 \%$, in MPI index by $42 \%$, and in poverty intensity by $6.2 \%$. Lastly, we observe that adult men are the most multi- 
dimensionally poor group followed by elderly women.
The next table (Table 3.2) shows multidimensional poverty by area type and age group.

Table 3.2: Multidimensional poverty by location and age group

\begin{tabular}{|c|c|c|c|c|}
\hline & & H (\%) & A & MPI \\
\hline \multirow{4}{*}{ Area type } & Urban & 20 & 0,86 & 0,172 \\
\cline { 2 - 5 } & Peri-urban & 5,8 & 0,966 & 0,056 \\
\cline { 2 - 5 } & Rural & 74,2 & 1,04 & 0,772 \\
\cline { 2 - 5 } Age group & Children & 12,5 & 0,976 & 0,122 \\
\cline { 2 - 5 } & Adolescents & 14,1 & 0,929 & 0,131 \\
\cline { 2 - 5 } & Adults & 46,8 & 0,991 & 0,464 \\
\hline
\end{tabular}

Source: Authors' calculations

We can conclude from Table 3.2 that multidimensional poverty is higher in rural areas $(77.2 \%)$ and poverty intensity $(74.2 \%)$ while multidimensional poverty is around $17 \%$ and poverty intensity is $20 \%$ in urban areas.
Table 3.3 displays the proportion (\%) of the population deprived in various indicators by gender and location.

Table 3.3: Proportion of population deprived in each indicator by gender and area type

\begin{tabular}{|c|c|c|c|c|c|c|}
\hline & Male & & & Female & & \\
\cline { 2 - 7 } Indicators & Urban & Peri-urban & Rural & Urban & Peri-urban & Rural \\
\hline Education & 1.64 & 0.45 & 5.36 & 1.18 & 0.28 & 2.81 \\
\hline Health & 0.26 & 0.07 & 0.6 & 0.41 & 0.11 & 0.82 \\
\hline Electricity & 5.96 & 1.78 & 24.1 & 6.44 & 1.82 & 23.9 \\
\hline Water & 0.58 & 0.27 & 6.03 & 0.6 & 0.27 & 5.56 \\
\hline Sanitation & 7.18 & 2.09 & 19.12 & 7.83 & 2.18 & 19.07 \\
\hline Housing & 1.98 & 1.28 & 19.29 & 2.07 & 1.33 & 19.26 \\
\hline Cooking fuel & 1.76 & 1.75 & 23.9 & 1.88 & 1.81 & 23.74 \\
\hline Assets & 1.19 & 0.34 & 4.55 & 1.28 & 0.344 & 4.68 \\
\hline
\end{tabular}

Source: Authors' calculations

As expected, the deprivation per indicator is much higher for rural residents than urban or peri-urban. The results also indicate that, more males than females in all areas experience the greater deprivation in education. However, from the health dimension more females are disabled than males in all areas since in Lesotho women experience gender-based violence and women may be at a greater risk of disability as chronic diseases become more prevalent. It is also widely accepted that older women suffer from high rates of disability than men. Even though, women tend to live longer than men they tend to suffer more from disabling but non-life-threating conditions, while men suffer from diseases that have higher mortality rates (Verbrugge and Wingard 1987). For the living standards, both males and females experience almost likely the same deprivations.

\subsection{Gender differences in poverty using an improved multidimensional poverty measure for adults and elderly}

The estimates of the improved multidimensional poverty measure that considers employment status for adults and elderly as a fourth dimension are presented in Table 3.4. We have assigned equal weights to each dimension $(25 \%)$ and set the second cutoff at $25 \%$, which means that it is qualitatively the same as the one used previously for the three-dimensional case $(33.33 \%)$. Individuals are considered multi-dimensionally poor if they are deprived in at least one dimension, such that the new findings are comparable with the previous ones. 
Table 3.4: Multidimensional poverty among adults considering employment and gender

\begin{tabular}{|c|c|c|c|c|c|}
\hline \multirow{2}{*}{ Measure } & & \multicolumn{3}{|c|}{ Differences between } \\
\cline { 2 - 6 } & & & \multicolumn{3}{|c|}{ females \& males estimates } \\
\hline Incidence & 72.5 & 27.2 & -45.3 & 0.38 & \\
\hline Intensity & 1.03 & 0.919 & -0.111 & 0.89 & \\
\hline MPI index & 0.75 & 0.25 & -0.5 & 0.33 & \\
\hline
\end{tabular}

Source: Authors' calculations

Overall, it can be seen from Table 3.4 that adding employment status as a fourth dimension which in this case men are more deprived than women since the textile industry in Lesotho is the most employer for Basotho and usually employs more females than male. The gender-gaps rise and multidimensional poverty seems feminized as men are more likely to be multi-dimensionally poor than women. However, it is important to point out that though there are high numbers of women in the textiles, apparel export-oriented industries, most of them are in low-paying grades, and their wage is below the average wage in the manufacturing sector while men are likely to occupy managerial jobs and earn remarkably higher wages than women.

\section{ROBUSTNESS ANALYSIS}

In this section, we are interested in assessing the sensitivity of estimates to the selection of

Table 4.1: MPI by gender and gender gap using five alternative weighting structures

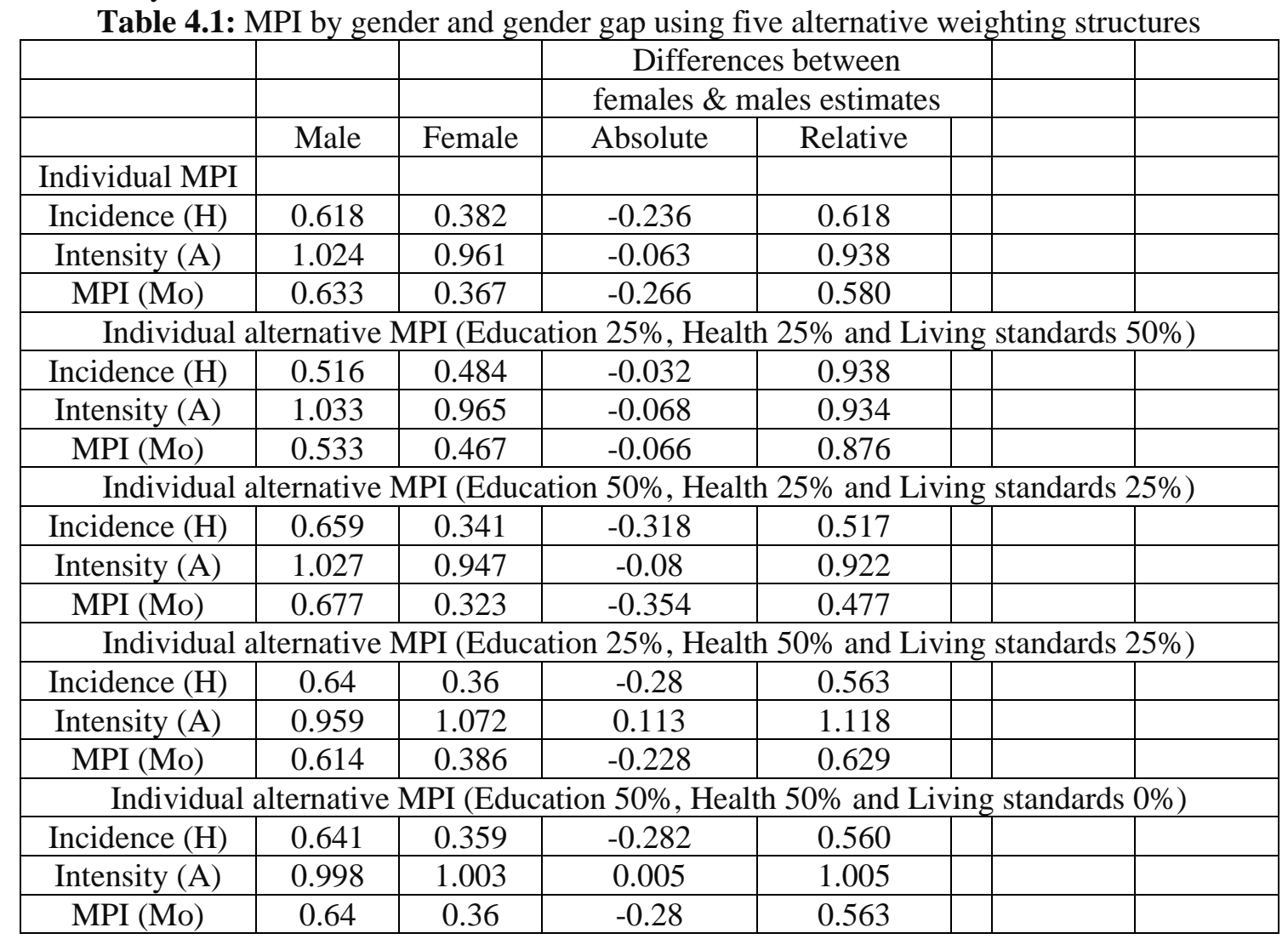

Source: Authors' calculations parameters. Thus, we want to find out if the main conclusions are robust to these choices. As a result, we examine if our conclusions are robust to a range of weights $(w)$. To do this we compute $H, A$, and $M_{O}$ using four additional weighting structures: i) giving $25 \%$ each to education and health and $50 \%$ to living standards, ii) giving $50 \%$ to education and $25 \%$ each to health and living standards, iii) Giving $25 \%$ each to education and standard of living and $50 \%$ to health, iv) giving $50 \%$ to both education and health and $0 \%$ to living standards to estimate the size of the gender gap.

Table 4.1 shows MPI by gender and gender gaps using the above-mentioned weighting structures. 
Considering the whole population, we find that looking at the gender gaps when compared to the baseline; the results indicate that the overall size of the differential is the same as that of the baseline. Male's multidimensional poverty headcount ratio dominates that of females, which means that MPI is severe in males than females. As a result, multidimensional poverty in Lesotho seems to

Table 4.2: MPI by age groups using five alternative weighting structures

\begin{tabular}{|l|l|l|l|l|l|}
\hline & Children & Adolescents & Adults & Elderly & Whole population \\
\hline $\begin{array}{l}\text { Individual } \\
\text { MPI }\end{array}$ & & & & & \\
\hline Incidence (H) & 0.125 & 0.141 & 0.468 & 0.266 & 0.117 \\
\hline Intensity (A) & 0.976 & 0.929 & 0.991 & 1.064 & 0.503 \\
\hline MPI (Mo) & 0.122 & 0.131 & 0.464 & 0.283 & 0.059 \\
\hline Individual alternative MPI (Education 25\%, Health 25\% and Living standards 50\%) \\
\hline Incidence (H) & 0.044 & 0.295 & 0.517 & 0.144 & 0.361 \\
\hline Intensity (A) & 1.182 & 0.929 & 0.986 & 1.139 & 0.415 \\
\hline MPI (Mo) & 0.052 & 0.274 & 0.51 & 0.164 & 0.15 \\
\hline Individual alternative MPI (Education 50\%, Health 25\% and Living standards 25\%) \\
\hline Incidence (H) & 0.149 & 0.11 & 0.456 & 0.285 & 0.098 \\
\hline Intensity (A) & 1 & 1 & 1.006 & 0.989 & 0.616 \\
\hline MPI (Mo) & 0.149 & 0.11 & 0.459 & 0.282 & 0.06 \\
\hline Individual alternative MPI (Education 25\%, Health 50\% and Living standards 25\%) \\
\hline Incidence (H) & 0.118 & 0.109 & 0.466 & 0.307 & 0.092 \\
\hline Intensity (A) & 0.856 & 1 & 0.979 & 1.091 & 0.477 \\
\hline MPI (Mo) & 0.101 & 0.109 & 0.456 & 0.335 & 0.044 \\
\hline Individual alternative MPI (Education 50\%, Health 50\% and Living standards 0\%) \\
\hline Incidence (H)
\end{tabular}

Source: Authors' calculations

Table 4.2 results agree again with the baseline that in Lesotho, adults are the most vulnerable age group in terms of multidimensional poverty followed by the elderly. In some cases, children and adolescents shift places. The main reasons for this result are the minimum years of education and the access to sources of income after retiring age e be feminized. While Espinoza-Delgado and Klasen, (2018) who proposed an individualbased multidimensional poverty framework for Nicaragua found that when using the same three-dimensional index poverty does not seem to be feminized in Nicaragua, both men and women are fairly likely to be multidimensionally poor.

Table 4.2 shows MPI by age groups using five alternative weighting structures

ither pension or remaining in the labour force. Access to health insurance and to effective healthcare in case of need are other contributing factors. Correa, (2017) in her work found that the elderly, as opposed to children, is the most multi-dimensionally deprived group.

Table 4.3 shows MPI by area type using five alternative weighting structures.

Table 4.3: MPI by area type using five alternative weighting structures

\begin{tabular}{|c|c|c|c|l|l|}
\hline & Urban & Peri-urban & Rural & & \\
\hline MPI & & & & & \\
\hline Incidence (H) & 0.2 & 0.058 & 0.742 & & \\
\hline Intensity (A) & 0.86 & 0.966 & 1.04 & & \\
\hline MPI (Mo) & 0.172 & 0.056 & 0.772 & & \\
\hline Individual alternative MPI (Education 25\%, Health 25\% and Living standards 50\%) \\
\hline Incidence (H) & 0.089 & 0.049 & 0.861 & & \\
\hline Intensity (A) & 0.966 & 0.98 & 1.006 & & \\
\hline
\end{tabular}




\begin{tabular}{|c|c|c|c|c|c|}
\hline MPI (Mo) & 0.086 & 0.048 & 0.866 & & \\
\hline \multicolumn{7}{|c|}{ Individual alternative MPI (Education 50\%, Health 25\% and Living standards 25\%) } \\
\hline Incidence (H) & 0.194 & 0.06 & 0.746 & & \\
\hline Intensity (A) & 0.907 & 0.95 & 1.027 & & \\
\hline MPI (Mo) & 0.176 & 0.057 & 0.766 & & \\
\hline \multicolumn{7}{|c|}{ Individual alternative MPI (Education 25\%, Health 50\% and Living standards 25\%) } \\
\hline Incidence (H) & 0.164 & 0.059 & 0.777 & & \\
\hline Intensity (A) & 1 & 1 & 1 & & \\
\hline MPI (Mo) & 0.164 & 0.059 & 0.777 & & \\
\hline Individual alternative MPI (Education 50\%, Health 50\% and Living standards 0\%) \\
\hline Incidence (H) & 0.222 & 0.063 & 0.715 & & \\
\hline Intensity (A) & 0.995 & 1 & 1 & & \\
\hline MPI (Mo) & 0.221 & 0.063 & 0.715 & & \\
\hline
\end{tabular}

Source: Authors' calculations

We found that looking at the area type, the analysis also shows that multidimensional poverty is higher in rural areas followed by urban and peri-urban. Lack of employment, poor paying jobs, poor access to health care and low education levels contribute to increased poverty rate. Masood et al., (2011) who estimated multidimensional poverty for four provinces of Pakistan also found that the most pervasive level of poverty exists in rural areas of different provinces.

\section{CONCLUSION AND POLICY IMPLICATIONS}

In this paper, we contribute to the literature on multidimensional poverty and gender inequality by proposing and applying a multidimensional poverty measure in Lesotho in order to estimate the gender differences in multidimensional poverty for the whole population.

We have found that in Lesotho, the multidimensional poverty incidence is estimated to be around $50 \%$, which remains a big problem. Multidimensional poverty is also high in rural areas $(77.2 \%)$ and poverty intensity (74\%) while in urban areas multidimensional poverty is around $17 \%$ and poverty intensity is $20 \%$. On average, the rural population suffers from deprivation in all the indicators considered in our analysis. When using a three-dimensional index (education, health \& living standards), the multidimensional poverty in Lesotho is feminized such that overall females are multidimensionally poorer than males. Adults were found to be the most vulnerable age group in terms of multidimensional poverty followed by the elderly. The driving factors for this result are the minimum years of education and the access to sources of income after retiring age either pension or remaining in the labour force. The results also indicate that, more males than females in all areas experience the greater deprivation in education. However, from the health dimension more females are disabled than males in all areas since in Lesotho women experience gender-based violence and women may be at a greater risk of disability as chronic diseases become more widespread. Gender differences are estimated to be above $20 \%$ in all age groups except for adults. These gender differences observed among children, adolescents and elderly are in favour of males, but the reverse is the case among adults: Adults men are worse off by $42 \%$ than females in terms of MPI index and by $39 \%$ in terms of incidence of poverty. The highest gender gap in poverty incidence and MPI index is found among children and the lowest among adolescents.

When comparing the estimated gender gaps to other works, we find that Klasen and Lahoti (2016), discovered that in India, the size of the gender gap is higher than 30\% except for intensity. While Espinoza-Delgado and Klasen (2018) who proposed an individual-based multidimensional poverty framework for Nicaragua found that when using the same three-dimensional index poverty does not seem to be feminized in Nicaragua, both men and women are equally likely to be multidimensionally poor.

When employment status is added as the fourth dimension to the analysis, we found that multidimensional poverty in Lesotho remains feminized; males are multi-dimensionally poorer than females. The gender gaps observed are above $60 \%$ in terms of poverty 
incidence and MPI index. This is different from work by Espinoza-Delgado and Klasen (2018) who found that, when adding a fourth dimension that considers employment, larger estimates of the incidence, intensity and inequality of women's poverty is observed. Our analysis is also different from Vijaya et al. (2013), Klasen and Lahoti (2016) and Wu Yichao and Qi Di (2017) who in their work to estimate individual multi-dimensional poverty analysis concluded that women face more deprivation than men. In terms of deprivation in dimensions among different age groups, we found that children are the most deprived group in education followed by elderly, adults and adolescents. Elderly are most deprived group in health followed by adults. In the living standard dimension, adolescents are the most multi-dimensionally poor group.

A strong policy implication that arises from our findings is the reduction of the urban-rural poverty gap. It is recommended that some serious protective measures to combat poverty should be taken in the rural areas to address equality issues to comprehend the Sustainable Development Goals (SDGs). From a gender perspective, the improved delivery of clean water and sanitation in rural areas would have large benefits for women in particular and are likely to yield significant progress towards gender equality. Lastly, the government should employ multidimensional poverty as one of the criterion in the allocation of fiscal resources.

Our work is also not exempt from limitations; we were only able to individualize deprivation data in some dimensions where available data allow such disaggregation. However, more and better individual data would be required for further work especially, in the living standards dimension in possession and use of assets. Moreover, it was mentioned in Section 1 that poverty is associated with feelings of powerlessness or vulnerability as well as threat from violence but in the 2016 population census dataset, no questions were asked relating to these indicators such as community crime rates or home system security among others. Therefore, to improve the construction of the MPI further, more data is required.

Conflict of Interest: The authors declare that they have no conflict of interest.

\section{REFERENCES}

- Alkire S, Foster J. (2011). Counting and multidimensional poverty measurement. Journal of Public Economics, 95(7-8): 476-487.

- Correa A. (2017). On the measurement of multidimensional poverty as a policy tool. Empirical applications to Chile, Colombia, Ecuador and Peru. Doctoral dissertation, Maastricht University, Netherland.

- Datt G. (2019). Multidimensional poverty in the Philippines, 2004-2013: How much do choices for weighting, identification and aggregation matter? Empirical Economics 57: 1103-1128.

- Espinoza-Delgado J, Klasen, S. (2018). Gender and multidimensional poverty in Nicaragua: An Individual-based Approach. University of Goettingen, Germany. MPRA paper No. 85263.

- Klasen, S. (2007). Gender-related indicators of well-being. In $M$. McGillivray (Ed.), human well-being. Concept and Measurement (pp. 167-192). New York, NY: Palgrave Macmillan.

- Klasen S, Lahoti R. (2016). How serious is the neglect of intra-household inequality in multi-dimensional poverty indices? Discussion papers, No. 200, Courant research centre, 'poverty, equity and growth in 40 developing and transition countries; Statistical Methods and Empirical Analysis', Georg-AugustUniversität Göttingen.

- Lesotho Country Analysis Final Report. (2017). Lesotho Country Analysis: Working Document Final Draft.

- Mc Lanahan SS, Sørensen A, Watson D. (1989). Sex differences in poverty, 19501980. Signs: Journal of Women in Culture and Society, 15(1): 102-122.

- Millennium Development Goals Status Report (2013) Kingdom of Lesotho, Maseru.

- Minister of Education and Training Chair, Multi-sectoral ECCD Policy Planning Working Group (2013). National policy for Integrated Early Childhood Care and Development. Kingdom of Lesotho. Maseru, Lesotho. 
- Masood SA, Muhammad W, Muhammad AA. (2011). Multidimensional poverty in Pakistan: Case of Punjab Province. Department of Economics, University of Sargodha, Pakistan. MPRA paper No. 32875 .

- OPHI (2017). OPHI Country Briefing 2017: Lesotho. Global Multidimensional Poverty Index (MPI) at a glance. Oxford Department of International Development. Queen Elizabeth House, University of Oxford.

- Rocchi A, Del Sette P (2016) Lesotho: Rural Development and Migration.

- Rodríguez L. (2016). Intra-household inequalities in child rights and well-being: A barrier to progress? World Development, 83: 111-134.

- United Nations (2015) Resolution adopted by the general assembly on 25 September 2015. United Nations General Assembly A/RES/70/1, Seventieth Session, Agenda items 15 and 116.
- Verbrugge IM, Wingard DL. (1987). Sex differentials in health and mortality: Women and Health. 1987; 12(2): 103-145.

- Vijaya R, Lahoti R, Swaminathan H. (2013). Moving from the household to the individual: Multidimensional Poverty Analysis. Retrieved from

- https://arxiv.org/ftp/arxiv/papers/1304/130 4.5816.pdf.

- Wiepking P, Maas I. (2005). Gender differences in poverty: A cross-national study. European Sociological Review, 21(3): 187-200.

- World Health Organisation and World Bank. (2011). World report on disability. World Health Organisation, Geneva.

- Wu Yichao, Qi Di. (2017). A genderbased analysis of multidimensional poverty in China: Asian Journal of Women's Studies, 23 (1). 